\title{
EXTENDED KALMAN FILTER BASED BRUSHLESS DC MOTOR FOR ROTOR POSITION AND SPEED CONTROL
}

This paper was downloaded from TechRxiv (https://www.techrxiv.org).

LICENSE

$\mathrm{CCO}$

SUBMISSION DATE / POSTED DATE

$15-12-2021 / 17-12-2021$

CITATION

Ellahi, Nabiya (2021): EXTENDED KALMAN FILTER BASED BRUSHLESS DC MOTOR FOR ROTOR POSITION AND SPEED CONTROL. TechRxiv. Preprint. https://doi.org/10.36227/techrxiv.17208848.v1

DOI

10.36227/techrxiv.17208848.v1 


\title{
EXTENDED KALMAN FILTER BASED BRUSHLESS DC MOTOR FOR ROTOR POSITION AND SPEED CONTROL
}

\author{
Nabiya Ellahi \\ MS Electrical Engineering, University of Engineering and Technology Lahore, \\ Lab Engineer, Institute of Electrical, Electronics \& Computer Engineering \\ University of the Punjab, Lahore, Pakistan
}

\begin{abstract}
A method to control speed and rotor position with improved performance has been described in this research. Various techniques are taken into consideration with their detailed description. During this process new methods are also introduced with their pros and cons. The research includes a detailed study of progressive back-Emf sensing strategies. The relevant methods, which can support estimation, are the back Emf zero-crossing method, integration of voltage, and position estimation by flux and inductance. In this thesis, Extended Kalman filter is utilized for position and speed estimation. Firstly, DC voltage will be applied as an input. Extended Kalman Filter is used to perform state estimation while PID controller is employed to regulate the system state following the reference signal. The proposed solution leads to control of the ripple generated in speed and torque of Brushless DC Motor and improved performance.
\end{abstract}

Key Words- Brushless De Motor, Extended Kalman Filter, back-EMF zero crossing, PID controller, speed and rotor position estimation

\section{I.INTRODUCTION}

Brushless Direct Current (BLDC) motor has many advantages such as removal of sparking, better speed versus torque characteristics, reduced noise operation, better ranges for speed, improved service life, and rugged construction, etc. Many studies have been performed on proper commutation, improvement in speed variation, minimization of torque ripples, and energizing of phases of BLDC motor [1]. In the past, many sensorless drive operations were proposed to reduce the expensive and weak position sensing for BLDC motors, including back-EMF sensing of voltage, integration of back-EMF, estimation of flux, and motor modification techniques. But unfortunately, none of these techniques worked well for different operating speeds, and there are reliability and complexity issues associated with them [2],[3]. These methods are unable to provide a continuous estimation of rotor position, so for high estimation accuracy, continuous information of rotor position is required not only every 60 electrical degrees [3]. The methods described have many benefits associated with them and can be applied for the estimation of rotor position. But despite it, all these methods have some problems associated with them, performance at low speed is inefficient, another inadequacy is variable ranges of the

speed of all these methods requires improvement. Mostly there were nonlinearities and perturbations in mechanical control objects [4]. The control design for the modeling of these parameters was also difficult. So because of all the above-mentioned limitations, these methods are not applied nowadays frequently, as they have some drawbacks. associated with them [5],[6]. So to overcome all these limitations some other methods should be applied. One of those methods that will be described in detail this research is Extended Kalman Filter. 
This technique will perform implementation in real-time.

The variables can be estimated by utilizing line voltages of stator and phase currents [7]. The parameters considered for the estimation algorithm has been described, and the other parameters which are to be estimated are the resistance of the stator, which can be approximated simultaneously by state variables of motor [8]. Extended Kalman Filter is an iterative technique for non-linear systems that are disturbed by noise. It utilizes a two-step algorithm in which the first state is to predict state estimate and error covariance estimate to get a predicted state estimate at present. In the next step predicted state estimate is corrected by utilizing recent process measurement to generate an estimate of the updated state [9],[10]. This technique is the online estimation method to approximate the speed and position of the rotor by utilizing calculations of stator line voltages and currents of a permanent magnet synchronous motor without utilizing a position sensor [11]. It is an online estimation process in which position and speed will be approximated by the application of the Extended Kalman Filter so that the maximum steady-state error between the reference and actual motor speed can be improved.

\section{METHOdS PROPOSED For SPEED AND RotoR POSITION APPROXIMATION:}

BLDC motors can be controlled in both sensored and sensorless mode. In order to minimize the total cost for actuating devices, sensorless techniques can be utilized. Total cost can be lowered by using this method. The disadvantage of sensorless control includes requirement of control algorithms and complex electronics [12]. In case of BLDC motor the shape of back-Emf is either sinusoidal or can be trapezoidal. Permanent magnet motors have different applications including industrial automation, computers, military, automotive and daily products of household due to numerous benefits and advantages. The nature of the BLDC motor is that it is electronically controlled and needs information of rotor position to perform commutation of currents in the stator. In the case of durability it is not advised to use the technique of position sensor [13]. The shape of back-Emf in a brushless dc motor is trapezoidal and that of stator currents is quasi rectangular. Three Hall sensors can do sensing of position so that current commutation can be performed after every 60 degrees. The BLDC motor needs a sensor of position that is resolver or encoder [14]. The main reason for utilizing this method is that they provide accurate information regarding rotor position and that is why position sensing technology using Hall sensors has been greatly observed [15]. In the most recent techniques rotor position is extracted every $60^{\circ}$ which is important to perform commutation. These methods are

\section{- Back-Emf of the motor}

- Conducting states detection from freewheeling diodes

- From third harmonic components having voltages 


\section{A. Back-EMF Zero-Crossing (Terminal Voltage Sensing):}

This is one of the most convenient methods for identification of zero crossing events and depends on identifying the events which will make back-Emf zero in the unexcited phase as soon as that phase will cross zero. The basic idea is that this zero crossing will activate the timer, so in the next interval, switching will take place at end of this timing instant. It is required for normal operation of BLDC motor both currents and back-Emf needs to be properly arranged so that the torque of constant value gets generated. The commutation of currents can be performed by detection of zero-crossing events of back-Emf, and in this case phase shift should be $30^{\circ}$ which can utilize commutation of six steps having inverter for running the BLDC motor [16]. Conduction instant is $120^{\circ}$ electrical for all the three phases. So conduction of current can take place through two phases, and the third phase is kept unexcited or floating. For the generation of maximum torque the inverter should perform commutation after every $60^{\circ}$, which is done by detection of zero crossing of back-Emf in the unexcited phase, so the current and voltage will be in the same phase. Speed change will not be affected much by delaying of $30^{\circ} \mathrm{from}$ the instants of zero crossing of back-Emf. Major drawback in this method is although it is simple but it is noise sensitive while identifying zero crossing and performance is much degraded while wide ranges of speed are required until timing instant is properly set according to the function of rotor speed [17]. Another disadvantage is noisy terminals of voltage cannot be utilized to get switching pattern at lower speeds as it is quite clear that the back-Emf is zero when machine is not moving and it has directly proportional relation with speed. The estimated switching events will have positional error when the period is transient and the speed is rapidly increased or decreased. So this method has reduced accuracy and detection of rotor position can take place up to $20 \%$ of the speed which is rated so the operating range of the speed gets lowered and is close to $1000-6000 \mathrm{rpm}$. When the speed is low or the motor is non-moving this method cannot be applied accurately [18]. In applications where high accuracy and wide ranges of speed are desired this method is not advisable since it will result in reduction of efficiency. At higher speeds due to the higher settling time of resonant in between inductance and capacitance can result in false detection of zero crossing. A solution to this issue is determine the back-Emf when the motor is running at high duty cycle so the transient will have enough time to settle down.

\section{B. Back-EMF Based Methods of Integration}

In this method, we can detect intervals of commutation by taking integration of the back-Emf in the floating or unenergized phase. Main feature is that the area in which integration is done will remain same at all speeds. The integration will get started once the silent phase will pass through zero points. Once the integrated area passes through a predefined value, which can be related to the points of commutation it can be stated that the phase current commutation is done [19]. If an operation is required to 
make the flux weak then it can be done by changing the specified value of voltage. The main benefit of this method is that the system will be less sensitive to changes in noise, and speed changes can be adjusted automatically, but again the performance of the system will become poor when the speed is low because of an accumulation of error and problems related to offsetting of voltage from integration. It is assumed that back-Emf will change linearly from positive cycle to negative cycle, and there is an assumption that the shape of back-Emf is trapezoidal, and due to the occurrence of linearly rising slope due to which speed will become insensitive, therefore the threshold value of voltage is kept constant[20]. To eliminate the chances in which the integrator will start from zero, again reset signal is kept on for sufficiently long period of time so that the integrator remains off until the remaining currents passes through zero crossings in the open phase [21]. The discrete current sensor will provide complete information of the current feedback, but the cost of each current sensor is quite high so it is not recommended to use it. A better solution to this problem is to utilize current sensors, which can be integrated by using power electronic devices such as MOSFET and IGBT, which are quite easily available in the market having wider range of ratings of hundred volts and current of few amperes.

All these methods were inaccurate to give continuous estimation of rotor position since they cannot be applied for sensorless operation where great approximation of rotor position and speed is of great importance. It is much required to approximate position of rotor continuously by utilizing measured values of voltages and currents so that estimation of flux linkage can be done[22].The approximated results are obtained from measured values of currents and voltages with a sampled time of 10 seconds. The precision of the results are dependent on the variation of the motor parameter and accurately measured values of voltages and currents

\section{ESTIMATION OF SPEED EMPLOYING EXTENDED KALMAN FILTER}

The estimation can be done by applying Extended Kalman Filter. First of all while approximation the current and voltage signals will not be filtered as in other methods they usually get filtered. The parameters which require approximation is basically of two parts one is speed and position of rotor which are estimated with parameters of motor and stator resistance can get approximated by using variables of motor state. From the results shown at the end of research it will be quite convenient for BLDC motor to approximate rotor position and speed with great precision in both states steady and dynamic [23]. By using stator resistance accuracy of approximation will be higher especially at low speeds. This technique performs optimal state estimation of dynamical nonlinear systems by applying signals that are disturbed by noise. The technique of Extended Kalman Filter is used for the approximation of parameters that are unknown like the resistance of stator $R_{r}$ and parameter estimation. The observer which is deterministic and has no noise is luenberger and can be applied to time-invariant linear systems [24]. EKF considers 
the noise sources having certain inaccuracies in measurements and modeling. Normally Kalman Filter is applied to linear systems and to nonlinear systems Extended Kalman Filter is applied [25]. The machine model is shown below.

$$
\begin{gathered}
\frac{d x}{d t}=A x+B V_{s} \\
x=\left[\begin{array}{llllll}
i_{a} & i_{b} & i_{c} & \omega & \theta & R_{s}
\end{array}\right]^{T} \\
V_{s}=\left[\begin{array}{lllll}
v_{a b} & v_{b c} & v_{c a}
\end{array}\right]^{T}
\end{gathered}
$$

Where

$\mathrm{i}_{\mathrm{a}}, \mathrm{i}_{\mathrm{b}}, \mathrm{i}_{\mathrm{c}}=$ Phase current

$\mathrm{V}_{\mathrm{ab}}, \mathrm{V}_{\mathrm{bc}}, \mathrm{V}_{\mathrm{ca}}=$ line to line voltages

$\mathrm{V}_{\mathrm{s}}=$ Input Vector
IV.MATHEMATICAL MODEL OF EXTENDED

\section{KALMAN FILTER:}

The Kalman Filter utilizes dynamic machine model in which the speed can be considered as a state as well as a parameter.

$$
\begin{gathered}
\mathrm{Y}=\mathrm{CX} \\
\mathrm{X}=\left[\begin{array}{llllll}
\mathrm{i}_{\mathrm{a}} & \mathrm{i}_{\mathrm{b}} & \mathrm{i}_{\mathrm{c}} & \omega & \theta & \mathrm{R}_{\mathrm{g}}
\end{array}\right]^{\mathrm{T}}
\end{gathered}
$$

$$
\mathrm{C}=\left[\begin{array}{llllll}
1 & 0 & 0 & 0 & 0 & 0 \\
0 & 1 & 0 & 0 & 0 & 0 \\
0 & 0 & 1 & 0 & 0 & 0
\end{array}\right]
$$

$\mathrm{A}=\left[\begin{array}{cccccc}1-\frac{\mathrm{RsT}}{\mathrm{L} s} & 0 & \frac{\mathrm{L}_{\mathrm{m}} \mathrm{R}_{\mathrm{r}}}{\theta \mathrm{L}_{g} \mathrm{~L}_{\mathrm{S}}^{\mathrm{g}}} & \frac{\mathrm{L}_{\mathrm{m}} \omega_{\mathrm{r}}}{\theta \mathrm{L}_{g} \mathrm{~L}_{g}} & 0 & 0 \\ 0 & 1-\frac{\mathrm{RsT}}{\mathrm{L} s} & \frac{-\mathrm{L}_{\mathrm{m}} \mathrm{R}_{\mathrm{r}}}{\theta \mathrm{L}_{g} \mathrm{~L}_{g}} & \frac{\mathrm{L}_{\mathrm{m}} \mathrm{R}_{\mathrm{r}}}{\theta \mathrm{L}_{g} \mathrm{~L}_{\mathrm{S}}^{\mathrm{S}}} & 0 & 0 \\ \frac{\mathrm{L}_{\mathrm{m}} \mathrm{R}_{\mathrm{r}}}{\mathrm{L}_{\mathrm{r}} \mathrm{L}_{\mathrm{r}}} & 0 & 1-\frac{\mathrm{R}_{g} \mathrm{~T}}{\mathrm{~L}_{g}} & -\omega_{\mathrm{r}} & 0 & 0\end{array}\right]$

$$
\mathrm{B}=\left[\begin{array}{ccc}
\frac{\mathrm{T}}{3 \mathrm{~L}_{\mathrm{S}}} & \frac{-\mathrm{T}}{3 \mathrm{~L}_{\mathrm{S}}} & 0 \\
0 & \frac{\mathrm{T}}{3 \mathrm{~L}_{\mathrm{g}}} & \frac{-\mathrm{T}}{3 \mathrm{~L}_{\mathrm{g}}} \\
\frac{\mathrm{T}}{3 \mathrm{~L}_{\mathrm{g}}} & 0 & \frac{-\mathrm{T}}{3 \mathrm{~L}_{\mathrm{g}}}
\end{array}\right]
$$

Description of Variables:

- $\mathrm{L}_{\mathrm{m}}=$ magnetizing inductance

- $\mathrm{R}_{\mathrm{r}}=$ Rotor resistance

- $\mathrm{R}_{\mathrm{s}}=$ Stator Resistance

$\bullet \theta=$ Rotor Position

- $\omega_{\mathrm{r}}=$ Rotor Speed

- $\mathrm{L}_{\mathrm{r}}=$ Rotor Inductance
To implement the Kalman filter in digital mode, the model needs to be discretized [26] and there are also some noise sources in the model which are denoted as $\mathrm{V}$ and $\mathrm{W}$ so in the discrete form model can be presented as

$$
\begin{aligned}
& X(k+1)=A_{d} X(k)+B_{d} U(k)+V(k) \\
& Y(k)=C_{d} X(k)+W(k)
\end{aligned}
$$

The variables can be considered independent of each other. Noise and statistics of measurements can be described by covariance matrices which are P,Q and R. The design of EKF involves some expressions which are computational. It includes two stages prediction and correction. In the first state predicted values $(\mathrm{k}+1)$ are found 
by the model of machine and the last values of the states which are estimated. Filtering stage starts from vector Q in which the estimated state $\mathrm{X}^{\wedge}(\mathrm{K}+1)$ can be found from the last prediction state in which there can be an addition of the term which is ek where $\mathrm{e}=\mathrm{Y}(\mathrm{K}+1)-\mathrm{Y}^{\wedge}(\mathrm{K}+1)$ and kalman gain. This gain can be used to optimize errors in state estimation [27]. The EKF calculations are done in such behavior so that correction term e approaches zero. Complete summary of EKF design comprises following six steps.

\section{A. Extended Kalman Filter Flow Diagram}

Step 1 Initialization of state vector and other matrices

$$
X(0), Q o, R o, P o
$$

Step 2 Prediction of state vectors

$$
X(k+1, k)=X(k+1)=A_{d} X(k)+B_{d} U(k)
$$

Step 3 Estimation of $\mathrm{P}(\mathrm{k}+1)$ which is covariance matrix

$$
P(k+1)=f(k+1) P(k) f T(k+1)+Q
$$

Step 4 Computation of Kalman Filter Gain

$$
\begin{aligned}
K(k+1)= & P(k+1) h(k+1)[h(k+1) P(k+1) \\
& h T(k+1)+R]
\end{aligned}
$$

Step 5 Estimation of state vectors

$$
X(K+1)=X(k+1)+K(k+1)[Y(k+1)]
$$

Step 6 Updating $\mathrm{P}^{\wedge}(\mathrm{K}+1)$ of covariance matrixes

$$
P^{\prime}(K+1)=P(K+1)-K(k+1) h(k+1) P(k+1)
$$

\section{B.Block Diagram with Extended Kalman Filter}

This block diagram comprises of various components, including DC input, inverter for switching, current sensors, BLDC motor, and an Extended Kalman Filter for approximation. In this research, we will use a brushless DC motor, which is a form of synchronous motor. To excite the motor, trapezoidal wave input is given to it, which can be done by making use of the analogy of switching by switching properly. Firstly we provide dc input to the circuit, and after that, the dc input is supplied to the MOSFET, which serves as an inverter, then the BLDC will run. Kalman Filter is used to create approximated values of voltages and currents from the terminals of the motor [28]. By using these values, it is fed to the PI controller and then to the logic table, which will perform switching. The PI controller will make electromagnetic torque as a reference. Hall Effect sensors will give a gate signal to the MOSFET, which will work on the position of the rotor and stator. Basically, the sensor will observe the position by detecting the electromagnetic force, which can be obtained by the positions of the stator and rotor. After that, the positions are fed into zero and one and then given to the proportional-integral controllers through converters, which are analog to digital. The non-linear system will refer to and after that perform switching of the motor [29]. The Extended Kalman Filter is applied to non-linear systems that can get linearized about an approximate of the mean current and covariance. If the EKF model is well-defined and also transitioned, it will generate an estimation of flux linkage of the stator, original velocity of the rotor, and utilizing values of voltage and current from the terminals of the motor can give alignment of stator flux. By using these values, the ripple generated in the torque can get managed by the 
PI controller of the BLDC motor, and at last, the ripple will get reduced [30]. Following Figure shows block diagram implementation of Brushless DC Motor Model with an Extended Kalman Filter.

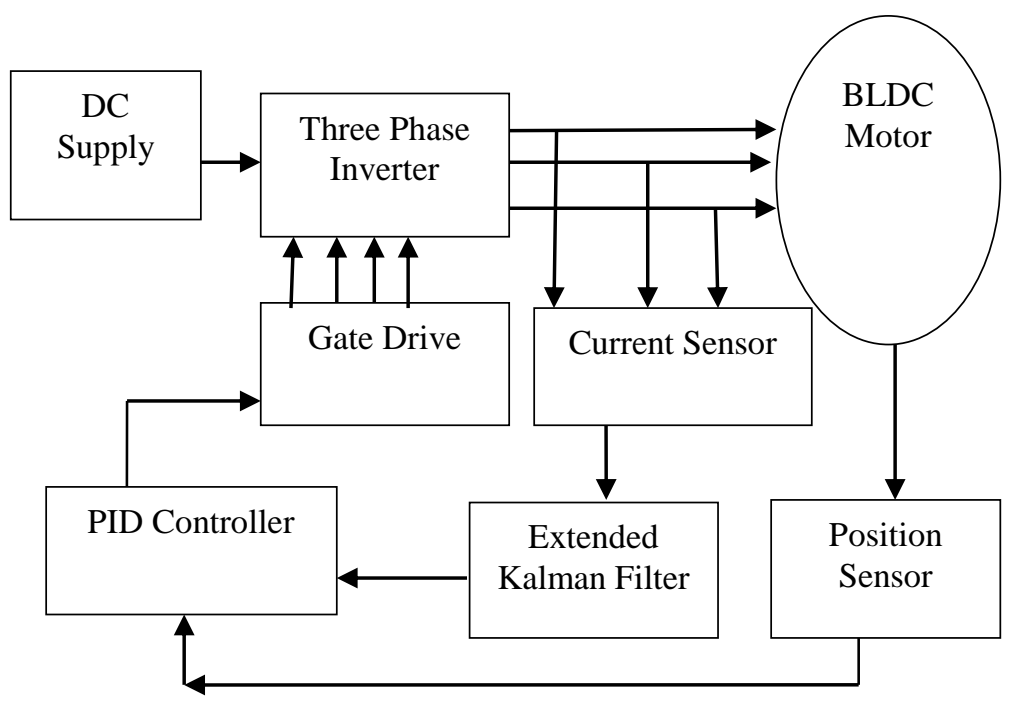

Figure 1 Show the Block Diagram of BLDC Motor with Extended Kalman Filter

\section{SIMULINK MODEL OF BLDC MOTOR WITHOUT EXTENDED KALMAN FILTER TECHNIQUE:}

To get the model of BLDC motor through Extended Kalman Filter simulation is performed in Simulink.

Other than the normal operation of the BLDC motor speed control the flux generated in the stator, and approximated values of mechanical state are obtained by Extended Kalman Filter. Extended Kalman Filter will be used to obtain an estimation of values of flux in the stator, the velocity of the rotor, and stator flux position through the calculated values of motor current and voltage, which is then given back to the logic gates of switching. Mostly Extended Kalman Filter technique is implemented on non-linear systems for the defined transition of the machine model. Firstly the current of the stator and speed of the rotor is obtained and applied to the random linear systems. The system can randomly pick the values by judging the system and then give it to the Kalman filter. This filter is a state observer, which is specially designed for the systems that are non-linear so that estimation of mechanical states can be obtained. The main advantage of the Kalman filter is that it is an observer of the state that can give the best estimation by minimizing the square error for the system of a state variable, which can be applied to both output and input of random disturbances. The machine model to get an estimation of motor speed without utilizing Extended Kalman Filter is shown below

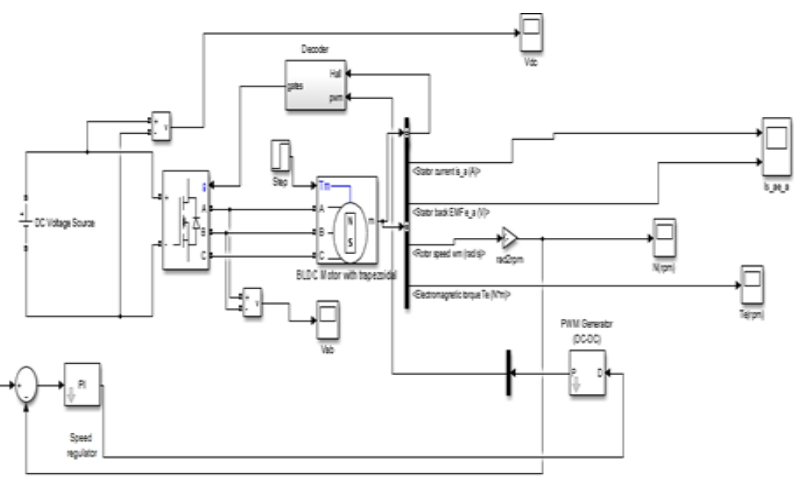

Figure 2 shows the BLDC Motor Model without Extended Kalman Filter

\section{PROPOSED SIMULINK MODEL FOR AN EXTENDED KALMAN FILTER TECHNIQUE:}

The simulink model to get an estimation of speed more accurately using an Extended Kalman Filter is shown below in the following figure. 


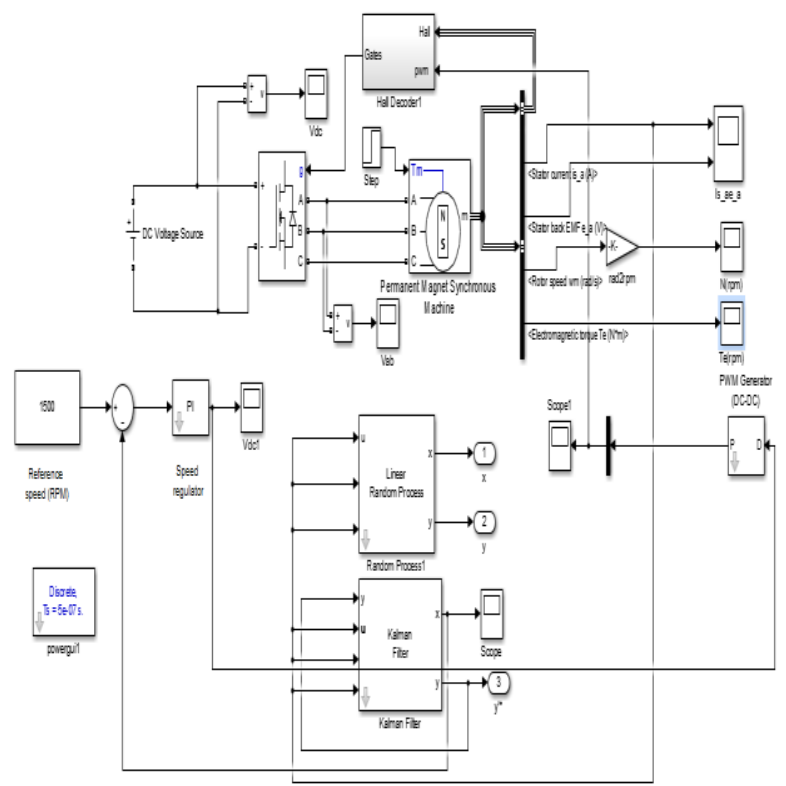

Figure 3 shows BLDC Motor Model with Extended Kalman Filter Technique

\section{Speed of Motor without Extended Kalman Filter:}

Constant steady-state speed cannot be generated as the ripple created in the torque is higher. In this case reference speed is $1000 \mathrm{rpm}$. Due to the presence of torque ripple initially, the value of speed increases slightly from the reference speed since no estimation technique is utilized to reduce the ripple. Motor Speed without an Extended Kalman filter is shown in figure given below.

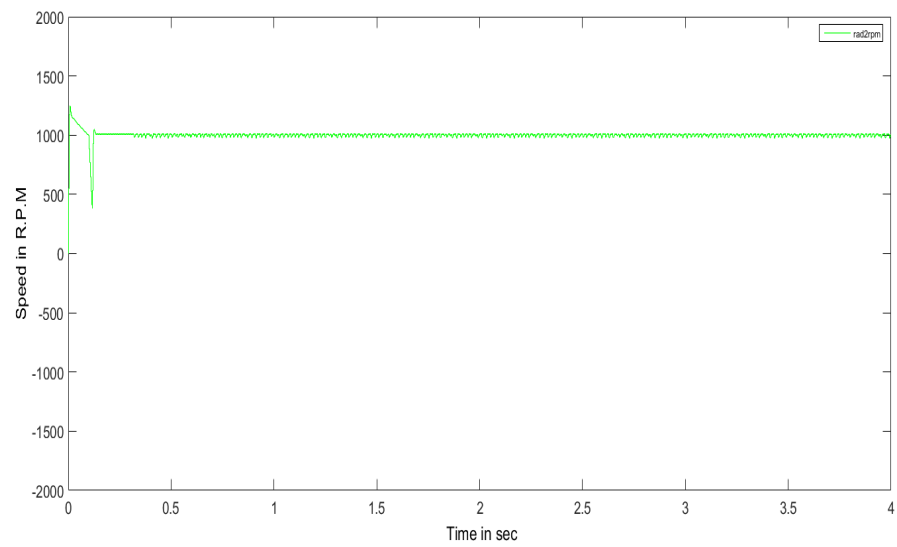

Figure 4 shows the Speed of Motor without Extended Kalman Filter
D. Speed of BLDC Motor with Extended Kalman Filter

The torque ripple is significantly reduced by utilizing

Extended Kalman Filter and the figure shows the speed of the Motor with Extended Kalman Filter Technique.

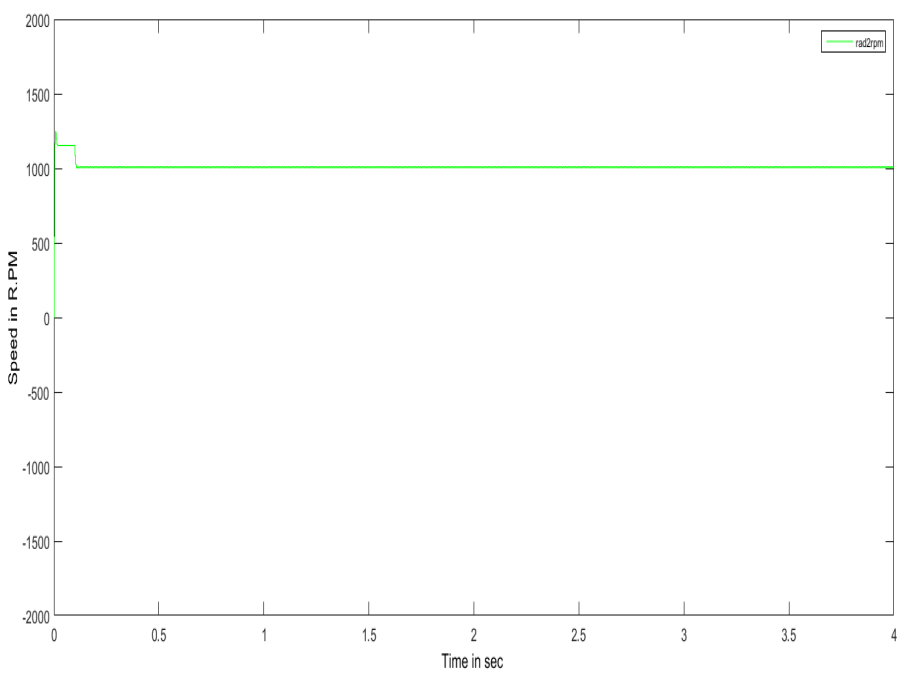

Figure 5 shows the Motor Speed with Extended Kalman Filter

\section{Torque in the BLDC Motor}

Ripple in the torque can be generated because of many reasons, including cogging of torque, the interaction of flux in the air gap, and MMF and harmonics, which can cause mechanical imbalance. As a result of this motor speed can get reduced. So Extended Kalman Filter technique is utilized to get an estimation of flux in the stator and mechanical state. Extended Kalman Filter is designed specially to get control of torque generated in the motor, and using this method, ripple can get managed in the system and by controlling torque-speed can also get controlled. Torque ripple can lead to a reduction of motor rated speed. The torque ripple can be found by many methods, including varying input voltage, current control algorithm, and control of frequency, unipolar and bipolar method. In this 
research, an Extended Kalman Filter will be utilized so that the ripple in the torque and speed gets minimized.

Following figure shows the torque ripple in the absence of Extended Kalman filter.

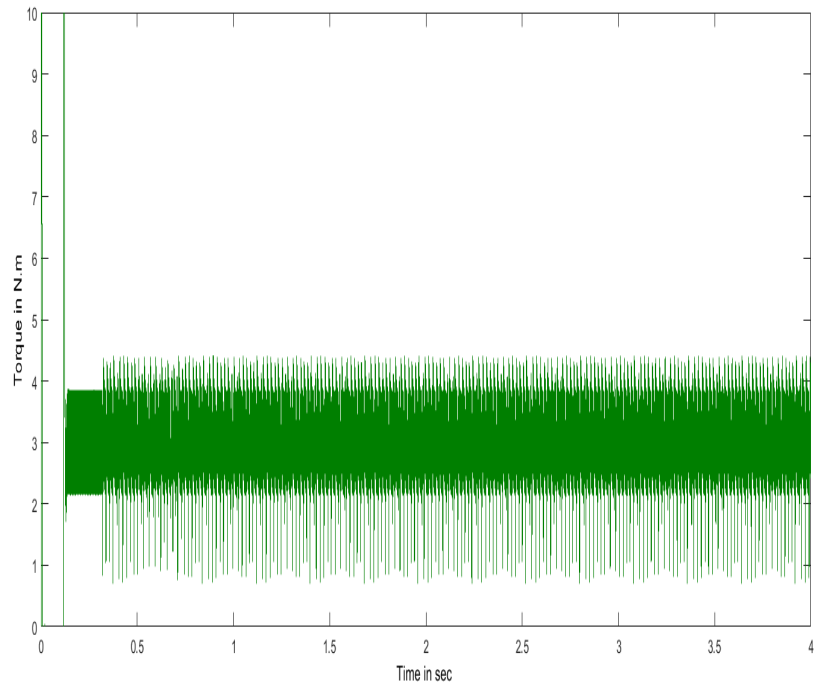

Figure 6 shows Torque of BLDC Motor without Extended Kalman Filter

However the torque ripple is significantly reduced by using extended kalman filter as shown by the following figure

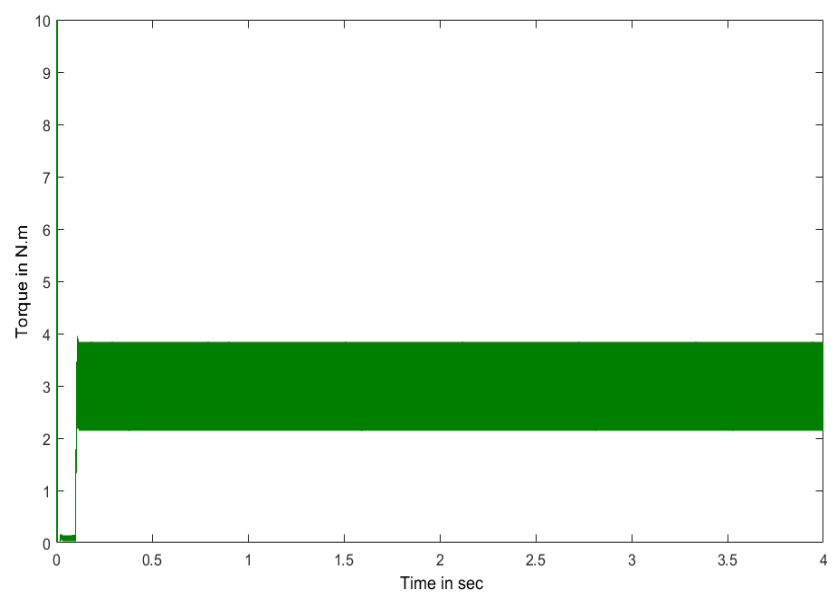

Figure 7 shows Torque of BLDC Motor with Extended Kalman Filter

\section{Stator Currents and Back-Emf:}

Stator Currents and Back-Emf of BLDC motor is shown in the figure given below
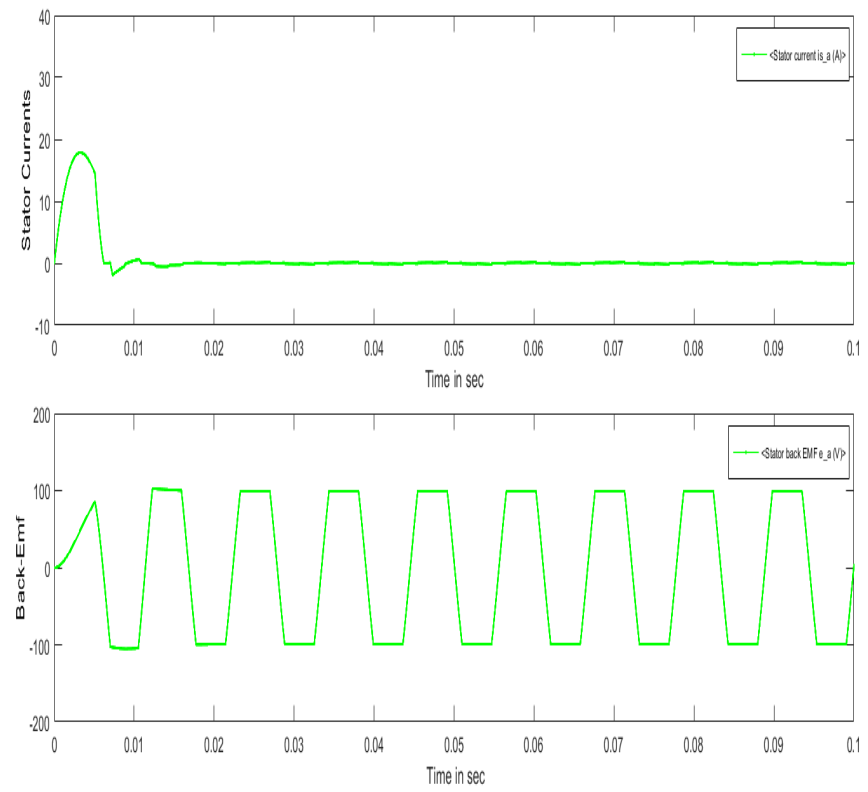

Figure 8 shows Stator Current and Back-Emf of BLDC Motor

\section{SWITCHING LOGIC OF THE PROPOSED SYSTEM}

The commutation of the phases is dependent on the values of the hall sensors. When coils of the motor are correctly given supply, the creation of a magnetic field will occur, and the movement of the rotor takes place. The most common method for running a BLDC motor is based on an on-off scheme. A coil will either conduct, or it won't conduct. The supply is given to the two windings, and the third winding is floating. If the connection of the coil is given to the neutral and power bus will result in the flow of current. This can be stated as a block or trapezoidal commutation. To give a command signal to the BLDC motor, a power stage dependent on the 3 half-bridges will be utilized. The figure below shows simulation of the proposed system. 


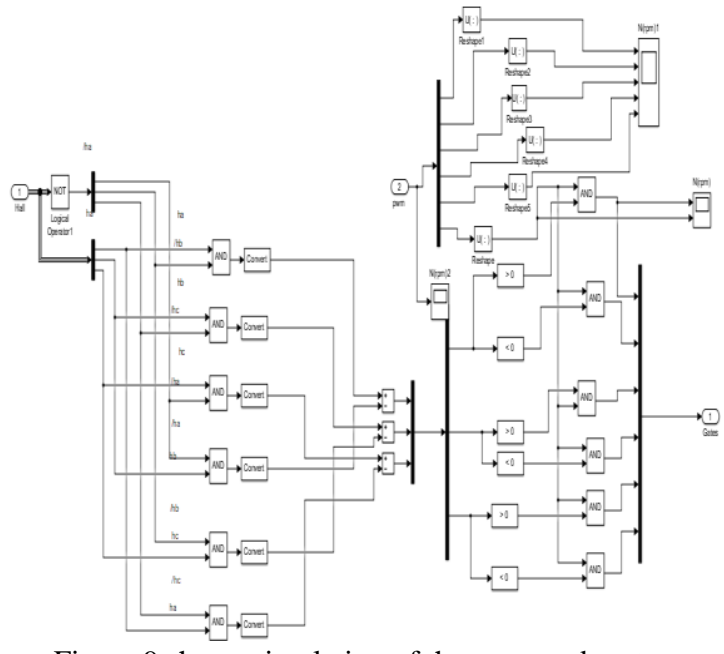

Figure 9 shows simulation of the proposed system

\section{CONCLUSION:}

The research clearly depicts nature of kalman filter based system of control is quite satisfactory. The parameters of machine including mechanical and electrical are completely changed from normal values which are basically utilized to design controllers for kalman filter so that incorrect positions of estimation can get initialized. So it can be clearly stated that undoubtedly Extended Kalman filter is widely used in different fields and research. From the results obtained from simulation this claim can be proved that it is one of the best methods being utilized for the purpose of speed and rotor position estimation. But there are also some limitations of this technique which can be overcome by proper initialization of motor parameters. Extended Kalman Filter has great and numerous benefits and applications, including precise estimation of rotor speed due to which it is applied in this research

\section{ACKNOWLEDGMENTS}

I would like to thank 'Allah Almighty' who bestowed the capability to work on such an arduous project. I would like to especially pay my compliments to my research supervisor, whose continued guidance and support have made me pass through numerous phases Last but not least, I would especially like to thank my family, including my parents. Without their support, I would not be able to do this. My friends for their guidance, support, love, and care, and my teachers who gave their precious feedback on my work. Honestly, nothing could have been made possible without the support of the above-mentioned personnel.

\section{REFERENCES}

"Microcomputer control for sensorless brushless motor," IEEE Trans. Ind. Application.

R. C. Beccerra, M. Ehsani, and T. M. Jahns, , "Sensorless Four Quadrant BLDC Motor,’ IEEE APEC’91, 1991, pp. 210-215.

H. Akagi and Su S. Ogasawara, "A perspective to sensorless drive for position of brushless dc motors," in Conf. Rec. IEEEIAS, 1980,pp. 453-457.

M. C. Moeira, "Indirect sensing of flux position for rotor of permanent magnet $\mathrm{AC}$ motors operating in different speed range," in Annu. Meeting, 1984, pp. 411-417.

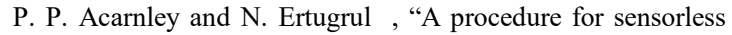
functioning of permanent magnet motors,". Ind. Applicat., vol. 40, filter," in EPE’94, vol. 3, Florence, Italy, 1981, pp. 
T. Klepsch, G. Henneberger and H. Brunsbach, , , "Position controlled permanent magnet synchronous motor without sensors," in, Brighton, U.K., 1983, pp. 28-33.

[8]

R. Dhaouadi, and L. Norum, "Implementation of an extended

Kalman filter for the state estimation of a permanent magnet motor," IEEE Trans. Power Electron., vol. 6, pp. 491-497,

D. M. Brod, "Current control of Voltage Source Inverter and Pulse Width Modulation inverters,"IEEE Trans., vol. IA-21, pp. 572580, June/July 1975.

[10] L. Loron, "Extended Kalman filter for parameters estimation of DC motors," in Proc. EPE'93,

BLDC-motor-drive-16_fig27_45267009

induction motors," in, U.K., 1995, pp. 75-80. J. Moore

Hall, 1979.

[14] R. Krishnan, "Initial algorithm of a PM DC brushless motor drive with zero position sensor," in Proc. IEEE PESC'89, 1989, pp. $815-821$

L. Cardolleti, "Sensorless position and speed control of a brushless DC motor from starting to normal speed," EPE J., vol. 4, pp. 35-44, Mar. 1982.

[16] B. Terzic, "Rotor position and speed approximation of brushless dc motor, "Ph.D. dissertation (in Croatian), Split, Croatia, 1988.
B. Terzic, "Brushless de motor without speed and position sensors," in Proc. PEMC'98, vol. 4, , Czech Republic, 1998, pp.4.704.75 .

[18] https://www.researchgate.net/figure/Typical-sensorless-BLDCmotor drive19_fig7_45267009

[19] A. M. Welekar, Advancement of Brushless DC Motor, IOSR Journal of Electrical and Electronics Engineering, 2004, $02-08$.

[20] Vinatha U, and Pola S, Recent Advancements in Control Schemes of BLDC Motors, IEEE International Conference on Technology, 2008, 417-422.
Ehsani M, Lee H.W, and T. Kim, Sensor less Brushless DC Motor/Generator Drives: Review and Future Trends, IET Power Applications, 2007, 1, 567-574.

[22] Jaime Gomez-Gil J. C. Gamazo-Real, and E. Vazquez-Sanchez, Speed and Position Control of Brushless DC Motors Using Sensor less Methods and Application Trends, Review, Sensors, 10, 2000, 6903-6957

[23] G. Zacharia and A. Raina, A Survey on Back EMF Sensing Methods for Sensor less Brushless DC Motor Drives, International Journal for Emerging Trends in Engineering Research, 2(2), 2014, 1519.

[24] T. Kim, and M. Ehsani, Sensor less Control of the BLDC Motors from Near-Zero to High Speeds, IEEE Transactions On Power Electronics, 19(6), 2004, 1635 - 1645.

[25] H.B Wang, Sensor less control method for brushless DC motor,

IET Electric Power Applications, 3(3), 2009, 250-25.

H. A. Toliyat and S. B. Ozturk, Indirect Flux and Direct Torque Control of Brushless DC Motor, IEEE/ASME Transactions On Mechanical, 16(2), 2011, 361-369.

[27] D. Nolan and J. Shao, Further Advancement of Direct Back EMF Detection for Sensor less Brushless DC (BLDC) Motor, Twentieth Annual IEEE Applied Power Electronics Conference and Exposition, 2, 2005, 923-927.

K. Cai, Z. Li , S. Cheng, and Y. Qin A Line-to-line Back EMF Calculation for Sensor less Brushless DC Motor, International Conference on Electrical Machines and Systems, 2008, 1416-1421. Y. Li and M. Lu, Design for Sensor less BLDC Motor Using Half-Bridge Driver Circuit, International conference on E service, E entertainment, 2010, 1-4.

[30] K. Vasudevan and P. Damodharan, Sensor less Brushless DC Motor Drive Based on the Zero-Crossing Detection of Back Electromotive Force (EMF) from the Line Voltage, IEEE Transactions On Energy Conversion, 15(3), 2010, 661 - 668. 


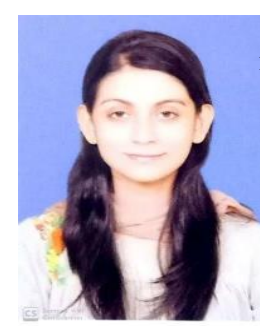

Nabiya Ellahi was born in Lahore, Pakistan

in 1994. She received her B.S Degree in

Electrical Engineering, University of the

Punjab Lahore in 2017 and M.S Degree

Electrical Engineering, University of

Engineering and Technology (UET)

Lahore in 2021.

In 2020 she was selected as a Lab Engineer.

in the Institute of Electrical, Electronics and

Computer Engineering (IEECE), University of the Punjab and since then she has been serving as a Lab Engineer. Her research interest includes power, electronics, BLDC motors and control systems. 